\title{
Report of a new educational programme to introduce dental students to special care dentistry
}

\author{
Janicke Liaaen Jensen ${ }^{1}$, Stefan Axelsson ${ }^{2}$ and Kari Storhaug ${ }^{2}$ \\ ${ }^{1}$ Department of Oral Surgery and Oral Medicine, Faculty of Dentistry, University of Oslo, Norway \\ ${ }^{2}$ TAKO-centre, Lovisenberg Diakonale Hospital, Oslo, Norway
}

\begin{abstract}
Introduction: According to the WHO, approximately $15 \%$ of the world's population has a chronic disease or disability, and individuals with impairment receive less oral health care than healthy persons. Dentists who are trained in communicating and treating patients with special needs are more likely to offer services to such groups. Therefore, teachers and specialists from the Dental Faculty and the TAKO centre developed a new educational programme related to oral surgery and oral medicine for dental students. The aim of the paper is to describe the programme and its evaluation by the students.

Methods: The programme was started in 2010 and has been adjusted over time. On the first day, the dental students are given a lecture outlining the subject and the programme. Then the students are divided into groups of 4-5. Each group is introduced to a rare diagnosis by the specialist team, they then meet and examine a patient; each group meets a different patient. The student groups later prepare a clinical case presentation about the actual diagnosis and the patient's oral health problems, outlining special treatment challenges and a treatment plan. At the end of the semester, the students present a total of 4-6 patients for the class. Finally, they fill in evaluation forms.
\end{abstract}

Results and conclusion: Between $86-100 \%$ of the students were positive or very positive to all parts of the programme which seems to be a useful way of elevating dental students' awareness of the complexity of special care patients and their treatment needs.

\section{Introduction}

According to the WHO approximately $15 \%$ of the world population has a chronic disease or disability, and individuals with impairments are less likely to receive health care services than healthy persons [1]. Many organizations, dental schools, and single individuals have been involved in changing this scenario. The book "Disability and Oral Care”, edited by Dr. June Nunn [2] was published by FDI some years ago to facilitate access to relevant literature for dental students and other professionals. Furthermore, the International Association for Disability and Oral Health has for many years been encouraging the development of educational programmes for undergraduate dental students to promote good oral health care for people with impairments world-wide $[3,4]$. These efforts are helpful, as several reports show that dentists who have received undergraduate training in how to communicate and treat patients with special needs are more likely to offer services to such groups [5].

The University of Oslo has been at the forefront of this trend. Already with the new curriculum in 1996, topics related to geriatric patients and persons with rare syndromes were introduced, thus providing the students with some knowledge, skills, and attitudes to meet oral health care needs of vulnerable patient groups [4]. However, as the number of patients requiring special care dentistry is increasing [1], we wanted to introduce the students to issues related to disability and oral care through a new educational programme directed at a subgroup of special needs patients, namely children and adolescents with rare syndromes with treatment needs related to oral surgery and oral medicine.

In Norway, a rare syndrome is defined as being less frequent than
$1: 10000$, meaning that any rare syndrome in Norway may comprise from 1 to 500 patients. In total, approximately 30000 Norwegians are affected by various rare conditions. Worldwide, between 6000 and 9000 different rare diagnoses have been described, making this into a very complex field. Many persons with rare syndromes affecting oral health in Norway are seen at the TAKO-centre. The TAKO-centre is a National Resource Centre for Oral Health in Rare Medical Conditions. It is a non-profit project financed by The Department of Health, and the services are offered free of charge to the patients. The centre was established 20 years ago at the Faculty of Dentistry, University of Oslo, but due to shortage of space, the centre moved to a nearby hospital after 5 years. Close cooperation between the two institutions has continued until this day. To our knowledge, it is the only centre worldwide where all individuals with a rare medical disorder affecting oral health can seek expert advice. The other Nordic countries do not have such a centre, and Hallberg et al. [6] complains that no-one in Sweden seems to take an overriding responsibility for the oral health of young patients with disabilities.

The TAKO-centre employs 9 dental specialists ( 6 of whom have a doctoral thesis), dental hygienists, speech pathologists, a physiotherapist and auxiliary staff. Patients with rare medical conditions are referred from the whole country for assessment, diagnosis, treatment planning, and treatment in some advanced cases. Research activity is high and

Correspondence to: Janicke Liaaen Jensen, Department of Oral Surgery and Oral Medicine, PO Box 1109, Blindern, 0317 Oslo, Norway, E-mail: jljensen@odont.uio.no

Received: January 29, 2016; Accepted: February 20, 2016; Published: February 24, 2016 
has focused on various conditions. Examples relevant to this paper are; ectodermal dysplasias [7-9], Williams syndrome [10], cherubism [11], osteogenesis imperfecta [12], and Ehlers Danlos syndrome [13]. The two latter papers on implant treatment in rare conditions are of special interest in this context. Most projects have been carried out in close collaboration with researchers at the Faculty of Dentistry, Oslo University Hospital, and other medical institutions in the Oslo region.

Many of the patients coming to the TAKO-centre need joint assessment by oral surgeons from the Dental Faculty and various specialists at the centre. However, over time, there has been little focus on such patients in undergraduate and postgraduate dental education in Norway within the curriculum of oral surgery and oral medicine. In 2010, we therefore proposed a programme for dental students in their fourth year as part of their education in oral surgery and medicine concentrating on patients with rare syndromes with treatment needs within oral surgery and oral medicine. The aims of the programme were to increase the understanding of rare medical conditions by exposing small groups of students to one patient/family with a rare diagnosis, focusing on the complexity of treating such conditions, to integrate the educational programmes of the two institutions, and finally to increase the dental students' skills in giving oral presentations by presenting clinical cases to their classmates. It is beyond the scope of this report to evaluate all these goals; its aim is to describe the programme and the evaluation by the students.

\section{Methods}

\section{Factors related to the new educational programme}

Student groups: The number of students in each group varied from 3-6.

Patients, diagnoses and consultation: The number of patients presented in total to a class varied from 4-8, necessitating the same number of consultations. The family had been called in advance and asked if they were willing to participate in a consultation with a number of students present in addition to the dental specialists. During the years, a number of various diagnoses have been presented (Table 1). The consultation includes patient history, the present problem, collection of data for treatment planning, and a tentative treatment plan. Plenty of time for communication between patient, parents, students, and the specialist team was set aside.

Treatment needs: The treatment needs includes preventive measures, orthodontics, extractions, surgical removal or exposure of teeth, frenulectomy, implants, biopsies, treatment of oral mucosal diseases, and prosthodontics.

Clinical case presentation: After the consultation, the students were asked to prepare a presentation comprising a clinical case description including facts on the particular syndrome, medical and oral implications, and treatment suggestions. Specified issues were to be discussed in the presentations: A description of the syndrome/ diagnosis, orofacial and dental characteristics, risk factors related to surgical procedures in the oral cavity, and special challenges of dental treatment. Furthermore, the students were told to make a 5-7 minute PowerPoint presentation, use photos/radiographs without identifying the individual patient, and refer to relevant literature. They were assigned a separate session for this preparation. At the day of presentation which was a three hour session, each student was involved in the presentation of one clinical case (the real patient they had seen) and listened to several [3-5] clinical case presentations by their peers. Specialists from the TAKO centre and the Faculty of
Dentistry were present at the presentations and commented on the contents. Afterwards, the students filled in evaluation forms on the new educational programme.

\section{Outline of the program:}

Day 1: A 45 min introduction about the centre, its philosophy and working methods and information about the educational programme.

Day 2: A group of students went to the TAKO-centre for 3 hours. Here they met a team of specialists (oral surgeon, orthodontist, prosthodontist, radiologist, paedodontist) who presented some background information about a selected rare syndrome and a patient case. Afterwards, the students met the actual patient and his or her parents and were present during the consultation.

Day 3: After the consultation, the students were asked to prepare a presentation for their peers comprising a clinical case description including facts on the particular syndrome, medical and oral implications, and treatment suggestions. They were assigned a separate session for this preparation.

Day 4: presentation of clinical cases for the class in a three-hour session, and evaluation of the programme.

As outlined for each student, the programme took place on four separate days. For the specialists, the programme was much more extensive, as "Day 2" was repeated with each group of students on separate days, and they all met a different patient.

\section{Evaluation of the new educational programme}

After the presentation of the clinical cases, at the end of the semester, the students were asked to evaluate all parts of the programme; the meeting with a real patient and the multidisciplinary team, working in groups, presenting a clinical case, and the clinical cases being presented by the other groups. The students scored their judgements as very positive, positive or less positive.

\section{Results}

\section{Factors related to the new educational programme}

Student groups: In our experience, the ideal number of a student
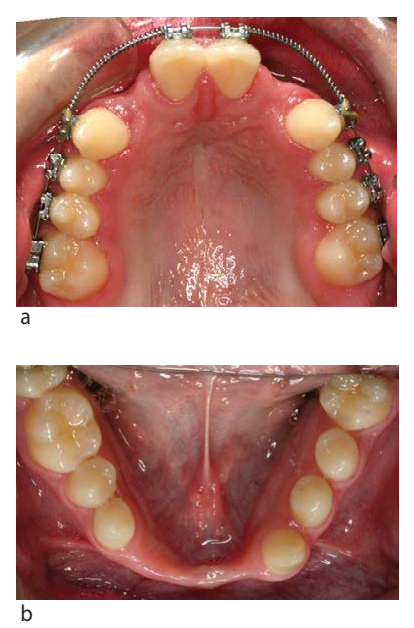

Figure 1. Ectodermal dysplasia: 17 year old boy with agenesis of 10 permanent teeth; four in the maxilla (a) and 6 in the mandible, and an extremely narrow alveolar ridge in the mandibular anterior region (b).

Examples of cases presented to the students. After the consultation, the students were asked to prepare a presentation comprising a clinical case description including facts on the particular syndrome, medical and oral implications, and treatment suggestions. 
Tanle 1. Over the years, the students have been exposed to the following rare diagnoses in alphabetical order:

\begin{tabular}{|l|}
\hline 1. Autoimmunepolyendocrine syndrome type 1 (APS 1) \\
\hline 2. Behçet's disease \\
\hline 3. Cerebral palsy with quadriplegia \\
\hline 4. Cleidocranial dysplasia \\
\hline 5. Ectodermal dysplasia \\
\hline 6. Ehlers Danlos syndrome \\
\hline 7. Hurler syndrome \\
\hline 8. Incontinentia pigmenti \\
\hline 9. Osteogenesis imperfecta \\
\hline 10. Partial monosomy/partial trisomy with oligodontia \\
\hline 11. Psycho-motor retardation with additional medical challenges \\
\hline 12. Rett syndrome \\
\hline 13. Rieger syndrome \\
\hline 14. SAPHO syndrome \\
\hline 15. SLC9A6 syndrome \\
\hline 16. Solitary median maxillary central incisor syndrome \\
\hline 17. Williams syndrome \\
\hline
\end{tabular}

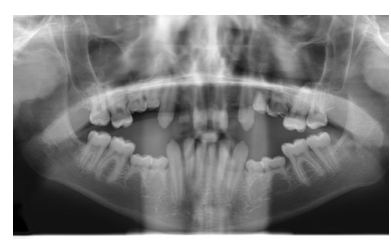

a

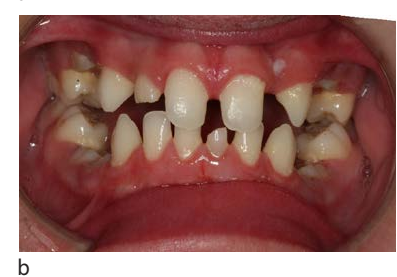

Figure 2. Williams syndrome: 13 year old boy with congenital agenesis of 11 permanent teeth, infraoccluding deciduous molars, bilateral open bite in the lateral segments, and mesial tipping of all permanent molars (a). Narrow permanent incisors (b).

Examples of cases presented to the students. After the consultation, the students were asked to prepare a presentation comprising a clinical case description including facts on the particular syndrome, medical and oral implications, and treatment suggestions.

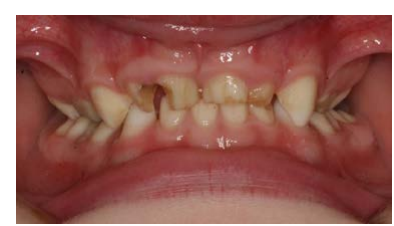

a

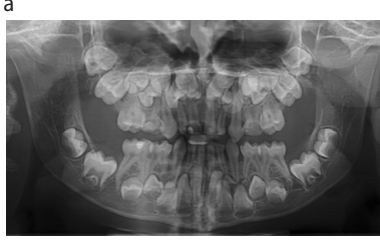

b

Figure 3. Cleidocranial dysplasia: 8 year old boy with retained deciduous teeth, hypomineralized and hypoplastic enamel (a). Non-erupted permanent teeth and supernumerary permanent teeth in the anterior maxillary region (b).

Examples of cases presented to the students. After the consultation, the students were asked to prepare a presentation comprising a clinical case description including facts on the particular syndrome, medical and oral implications, and treatment suggestions.

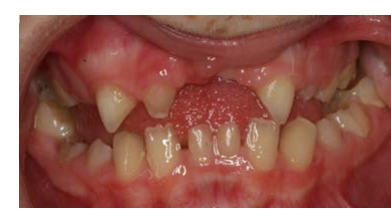

a

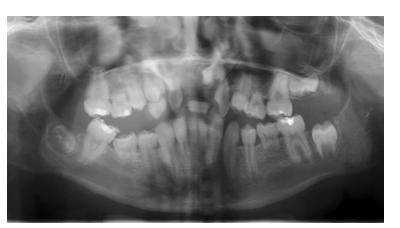

Figure 4. Rieger syndrome: 13 year old girl with agenesis of 12 permanent teeth and a hypertrophic maxillary frenulum (a). Infraoccluding deciduous molars, few occlusal contacts, impacted left maxillary canine (b).

Examples of cases presented to the students. After the consultation, the students were asked to prepare a presentation comprising a clinical case description including facts on the particular syndrome, medical and oral implications, and treatment suggestions.

group is 4, provided that the consultation room is big enough to hold a patient, the parents, three or four specialists and four students. With 5 students, it gets too crowded and 3 students only will elevate the number of groups and patients needed. A group of 4 students also seems to work well together.

Patients, diagnoses and consultation: Over the years, the students have been exposed to a variety of diagnoses (Table 1). In the present educational programme, the patient must at the same time have a rare syndrome of interest and be in need of oral surgical or oral medicine treatment. Therefore, the patients most frequently included were those with oligodontia in combination with ectodermal dysplasia (Figure 1) or Williams syndrome (Figure 2), as these patients often are in need of a combination of orthodontic, prosthodontic and surgical treatment and possibly implant treatment as adults. Ectodermal dysplasias are a big and heterogeneous group of conditions both clinically and genetically; almost 200 different types exist. At least two of the ectodermal derivatives hair, nails, sweat glands/ skin, or teeth must be affected. Williams syndrome includes mental retardation of varying degree, special facial characteristics, growth retardation, heart defects, oversensitivity to sounds, anxiety, musical talent, fondness of people and "cocktail party chattering". Cleidocranial dysplasia (Figure 3) is characterized by missing or underdeveloped clavicular bones, delayed development of bones of the skull, and deviations in tooth development with retained and supernumerary teeth. Treatment includes many rounds of surgical extractions or exposure, and long term orthodontic treatment. Consequently, this condition makes a good teaching example. Finally, Rieger syndrome (Figure 4) with the unusual lack of maxillary central incisors is another good example. Other characteristics of Rieger syndrome are iris atrophy, skin abnormalities, a flat midface, and a hyperplastic frenulum. The four cases in Figures 1-4 all illustrate that the dentist may be the first to notice the lack of teeth or the presence of supernumerary teeth. A good case related to oral medicine, is the patient with autoimmune polyendocrine syndrome type 1 who amongst numerous endocrine problems (hyperparathyroidism and Addison's being the most common), suffer from mucocutaneous candidosis, a condition that can be detected and diagnosed by an alert and well educated dentist.

The consultation normally took 45 minutes with radiographs taken 
in advance, and the learning experience was influenced by the quality of the communication between the patient, the parents, the specialists, and the students, requiring that at least one of the specialists knew the patient in advance.

Treatment needs: The treatment needs should be as outlined and not be so advanced that the students had no insight into the treatment options. The students were in the fourth year of the five year curriculum. The students may have profited more in terms of understanding the treatment options if they had been more advanced in their learning curve, but they expressed that they were very satisfied with getting this offer in the fourth year as it widened their horizon of what being a good dentist implies.

Clinical case presentation: Between 4 and 6 patients were presented during a three hour session. In our experience, four conditions are enough, maximum five. Limiting the number of clinical cases to be presented, improved the learning experience for the audience. To avoid making the student groups too big, two groups can see the same condition, but not the same patient as that would increases the burden on the patient. At the day of presentation, the students can be asked to emphasize different aspects of the condition and the treatment. After our first experience with this programme, the students were told to present only the most important aspects about the various syndromes and not all the literature they could possibly find.

Outline of the programme: Many ways of outlining the programme were tested, and it was adjusted over time, inferior outlines are not presented as no proper evaluation was performed. We recommend a joint lecture at the start of the programme, followed by presentations of conditions and patients for groups of four students. Thereafter, the students work within their groups. Finally, each group presents a clinical case, four - five conditions in total, to their peers.

\section{Evaluation by the students}

The programme has now been tested on seven groups of students (spring 2010, autumn 2010, spring 2011, autumn 2011, spring 2013, autumn 2013, and spring 2014.) At the end of the programme, the students filled in an evaluation form. Overall, the new educational programme was very well received by the students (Table 2). They emphasized that meeting a real patient with a rare condition made a great impression. Similarly, they were very positive to meeting the multidisciplinary team and to observe the way of working and communicating with the patient and the family. The students enjoyed working in groups, presenting a clinical case, and to the clinical cases being presented by the other groups. They all wanted the programme to continue, but most students felt that being at the centre once in this context was enough.

\section{Discussion}

Traditionally, dental education has focused on healthy patients; whereas special needs patients have been included gradually over the last decades. According to Dougall et al. [4], leading institutions are now embedding teaching and learning in special care dentistry (SCD) within their curricula, and the University of Oslo has done so since 1996. However, as the number of patients requiring special care dentistry is increasing [1], we wanted to extend the existing curriculum. This paper describes a new educational programme to introduce dental students to patients with rare medical conditions with treatment needs related to oral surgery and oral medicine. The programme combines real patients and presentations of clinical cases. By this combination, the students' experience is enhanced. Braeckman et al. [14] compared work place visits and clinical cases in undergraduate occupational medicine teaching and showed that depending on the interest, experience, and resources of teachers, both were effective. However, awareness of risk factors and preventive measures were higher in students who had met real patients.

The programme has been a success and is now continued on a permanent basis. Meeting a patient with a rare syndrome made a great impression on the students. It must be emphasized that some parents may be important resources for insight into the rare condition of their child and they may even be involved with the actual patient group. The communication with the parents in front of the students is therefore very valuable. A happy patient with Williams syndrome on one hand, and a withdrawn patient and silent parents on the other hand, give different but important insights into the joys and difficulties of a rare syndrome. A patient no-show is the worst scenario, leaving the students with no real patient experience. For such a situation, clinical presentations were made in advance, but fortunately had to be used only once. To initiate a programme related to rare syndromes, dedicated and experienced teachers are mandatory. As Thierer and Meyerowitz [15] pointed out, efforts to increase the pool of providers willing and able to care for special needs patients comes with a price tag and a substantial commitment of resources. The present programme is cost demanding, requiring many skilled specialists who are interested in teaching to be present at the same time. It may also be difficult to find patients and families who are willing to participate in such a programme including exposure to many students. Thus, the pool of patients must be sufficient. The ethical aspects must be taken into consideration as well; there is a very fine balance between teaching and making the session into a show of a patient with different appearance and behaviour. Other approaches including filming the consultation in the presence of the specialist team only, with simultaneous transmission to a bigger group of students, may be considered to lower the time involved and the burden put on the patient and the family.

In this programme, each student acted both as a presenter and as part of the audience. Thus the programme stimulates the students' ability to contribute to their own learning, putting part of the teachers' normal duties on the students in letting them present clinical cases for each other. The quality of the presentations is partly dependent on how well the groups work, and most of the students were indeed satisfied with the work in the group. However, they were put together

Table 2. Dental students' evaluation of the new educational programme.

\begin{tabular}{|c|c|c|c|c|c|c|c|}
\hline & \multicolumn{7}{|c|}{ Percentage answering positive or very positive to the questions (\%) } \\
\hline & Spring 2010 & Autumn 2010 & Spring 2011 & Autumn 2011 & Spring 2013 & Autumn 2013 & Spring 2014 \\
\hline Experience of meeting a patient with a rare syndrome & $87 *$ & 97 & 97 & 100 & 100 & 100 & 100 \\
\hline Experience of meeting the specialist team & 97 & 100 & 100 & 100 & 100 & 100 & 100 \\
\hline The group's function in planning and making the clinical presentation & 100 & 94 & 86 & 96 & 100 & 100 & 100 \\
\hline Learning experience of presenting a clinical case for the class & 97 & 94 & 100 & 96 & 92 & 100 & 96 \\
\hline Learning experience of the other clinical case presentations & 97 & 91 & 93 & 96 & 100 & 100 & 100 \\
\hline
\end{tabular}

*One group of four students did not meet a patient because of acute illness and therefore did not answer this question. 
alphabetically and not according to students' preferences. Other ways of putting groups together might have been considered. According to Thurman 2009 [16], students may need advice in how to function as a group. Another factor relevant to the quality of the presentation and the learning outcome for the audience are clear didactic instructions. Finally, some rare conditions and surgical treatment needs are better teaching tools than others as demonstrated by Figures 1-4.

We have not compared our teaching methods to others, whether this approach is superior to others or not, is not evaluated in this paper. Our aim is simply to present the educational programme and to show that it was very well received by the students. The outline of combining real patients and clinical cases to be presented by the student in a class setting, may also be used in other patient groups and clinical situations. According to Thompson et al. [17], undergraduate training should provide sufficient exposure to enable students to care for patients with specific medical, physical or mental health problems and to know the appropriate pathways for referral of patients they are unable to treat or who require further assessment. With this programme, it is hoped that the sum of meeting the real patient and the presentation of the clinical cases will lead the future dentist to reflective thinking and appropriate actions. As repetition is the best way of learning, all dental students will also attend a 3 hour session with patients at the TAKO-centre in their last semester before graduation focusing on other aspects of rare conditions.

\section{Conclusions}

The new educational programme was very well received by the students. A combination of meeting a real patient and exposure to clinical cases seems to be a useful way of elevating dental students' awareness of the complexity of special care patients and their treatment needs.

\section{Acknowledgments}

We thank the other members of the specialist team and all the patients for their contribution to the new educational programme.

\section{References}

1. Thomas-Crusells J, McElhaney JE, Aguado MT (2012) Report of the ad-hoc consultation on aging and immunization for a future WHO research agenda on lifecourse immunization. Vaccine 30: 6007-6012.[Crossref]
2. Nunn J (2000) Disability and oral care. International Association for Disability and Oral Health and FDI. FDI World Dental Press, London, UK

3. Dougall A, Pani SC, Thompson S, Faulks D, Romer M, et al. (2013) Developing an undergraduate Curriculum in Special Care Dentistry - by consensus. Eur J Dent Educ 17: 46-56. [Crossref]

4. Dougall A, Thompson SA, Faulks D, Ting G, Nunn J (2014) Guidance for the core content of a Curriculum in Special Care Dentistry at the undergraduate level. Eur J Dent Educ 18: 39-43.[Crossref]

5. Faulks D, Freedman L, Thompson S, Sagheri D, Dougall A (2012) The value of education in special care dentistry as a means of reducing inequalities in oral health. Eur J Dent Educ 16: 195-201.[Crossref]

6. Hallberg U, Strandmark M, Klingberg G (2004) Dental health professionals' treatment of children with disabilities: a qualitative study. Acta Odontol Scand 62: 319-327. [Crossref]

7. Nordgarden H, Jensen JL, Storhaug K (2001) Oligodontia is associated with extraoral ectodermal symptoms and low whole salivary flow rates. Oral Dis 7: 226-232. [Crossref]

8. Nordgarden H, Jensen JL, Storhaug K (2002) Reported prevalence of congenitally missing teeth in two Norwegian counties. Community Dent Health 19: 258-261. [Crossref]

9. Nordgarden H, Storhaug K, Lyngstadaas SP, Jensen JL (2003) Salivary gland function in persons with ectodermal dysplasias. Eur J Oral Sci 111: 371-376.[Crossref]

10. Axelsson S, Bjørnland T, Kjaer I, Heiberg A, Storhaug K (2003) Dental characteristics in Williams syndrome: a clinical and radiographic evaluation. Acta Odontol Scand 61: 129-136.[Crossref]

11. Prescott T, Redfors M, Rustad CF, Eiklid KL, Geirdal AØ, et al. (2013) Characterization of a Norwegian cherubism cohort; molecular genetic findings, oral manifestations and quality of life. Eur J Med Genet 56: 131-137.[Crossref]

12. Jensen JL, Brox HT, Storhaug K, Ambjørnsen E, Støvne SA, et al. (2011) Dental implants in patients with osteogenesisimperfecta and a review of the literature. Oral Surgery 2011: 4: 105-114.

13. Jensen JL, Storhaug K (2012) Dental implants in patients with Ehlers-Danlos syndrome: a case series study. Int J Prosthodont 25: 60-62.[Crossref]

14. Braeckman L, Bekaert M, Cobbaut L, De Ridder M, Glazemakers J, et al. (2009) Workplace visits versus case studies in undergraduate occupational medicine teaching. J Occup Environ Med 51: 1455-1459.[Crossref]

15. Thierer T, Meyerowitz C (2005) Education of dentists in the treatment of patients with special needs. J Calif Dent Assoc 33: 723-729.[Crossref]

16. Thurman J, Volet SE, Bolton JR (2009) Collaborative, case-based learning: how do students actually learn from each other?J Vet Med Educ 36: 297-304.[Crossref]

17. Thompson S, Griffiths J, Hunter L, Jagger R, Korszun A, et al. (2001) Development of an undergraduate curriculum in special care dentistry. $J$ Disabil Oral Health 2: 71-77.

Copyright: (C2016 Jensen JL. This is an open-access article distributed under the terms of the Creative Commons Attribution License, which permits unrestricted use, distribution, and reproduction in any medium, provided the original author and source are credited. 